\title{
A Longitudinal Study of Paternal Mental Health During Transition to Fatherhood as Young Adults
}

WHAT'S KNOWN ON THIS SUBJECT: There is growing

understanding of the detrimental effect of paternal depression on children. The transition to fatherhood is a unique time for men. Identifying which fathers are at-risk and when will inform effective methods to help men and their families.

WHAT THIS STUDY ADDS: Nonresident fathers have the highest depression symptom scores, peaking before entering fatherhood. Although resident fathers' scores decrease preceding entry into fatherhood, there is a significant increase from 0 to 5 years of their child's life when key parent-infant attachment occurs.
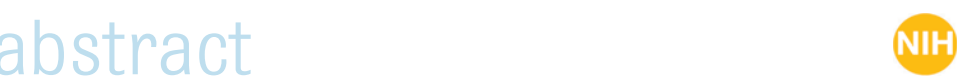

BACKGROUND AND OBJECTIVE: Rates of paternal depression range from $5 \%$ to $10 \%$ with a growing body of literature describing the harm to fathers, children, and families. Changes in depression symptoms over the life course, and the role of social factors, are not well known. This study examines associations with changes in depression symptoms during the transition to fatherhood for young fathers and whether this association differed by key social factors.

METHODS: We combined all 4 waves of the National Longitudinal Study of Adolescent Health to support a 23-year longitudinal analysis of 10623 men and then created a "fatherhood-year" data set, regressing ageadjusted standardized depressive symptoms scores on fatherhood status (nonresidence/residence), fatherhood-years, and covariates to determine associations between Center for Epidemiologic Studies Depression Scale scores and fatherhood life course intervals.

RESULTS: Depressive symptom scores reported at the entry into fatherhood are higher for nonresident fathers than nonfathers, which in turn are higher than those of resident fathers. Resident fathers have a significant decrease in scores during late adolescence $(\beta=-0.035$, $P=.023)$, but a significant increase in scores during early fatherhood $(\beta=0.023, P=.041)$. From entrance into fatherhood to the end of early fatherhood ( +5 years), the depressive symptoms score for resident fathers increases on average by $68 \%$.

CONCLUSIONS: In our Iongitudinal, population-based study, resident fathers show increasing depressive symptom scores during children's key attachment years of $0-5$. Identifying at-risk fathers based on social factors and designing effective interventions may ultimately improve health outcomes for the entire family. Pediatrics 2014;133:836-843
AUTHORS: Craig F. Garfield, MD, ${ }^{a, b, c}$ Greg Duncan, PhD, ${ }^{d}$ Joshua Rutsohn, MPH, ${ }^{a}$ Thomas W. McDade, PhD, ${ }^{\text {cee }}$ Emma K. Adam, PhD, c,f Rebekah Levine Coley, PhD, ${ }^{8}$ and P. Lindsay Chase-Lansdale, PhD ${ }^{\text {c,f }}$

aNorthwestern University Feinberg School of Medicine, Departments of Pediatrics and Medical Social Sciences, Chicago,

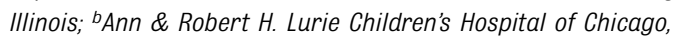
Chicago, Illinois; ' Institute for Policy Research, Northwestern University, Evanston, Illinois; aSchool of Education, University of

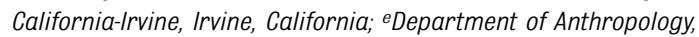
Northwestern University, Evanston, Illinois; ' SChool of Education and Social Policy, Northwestern University; 'Lynch School of Education, Boston College, Chestnut Hill, Massachusetts

\section{KEY WORDS}

fathers, depression, parent-infant/child interaction, father involvement, longitudinal study

\section{ABBREVIATIONS}

Add Health-The National Longitudinal Study of Adolescent Health

CES-D - Center for Epidemiologic Studies Depression Scale GEE-generalized estimating equation

Dr Garfield conceptualized and designed the study, coordinated and supervised data analysis drafted the initial manuscript, and reviewed and critically revised the manuscript; Drs Duncan, Coley, and Chase-Lansdale conceptualized and designed the study, carried out the initial analyses, and reviewed and critically revised the manuscript; Mr Rutsohn coordinated and supervised data analysis and reviewed and critically revised the manuscript; Drs McDade and Adam carried out the initial analyses and reviewed and critically revised the manuscript; and all authors approved the final manuscript as submitted

www.pediatrics.org/cgi/doi/10.1542/peds.2013-3262

doi:10.1542/peds.2013-3262

Accepted for publication Jan 27, 2014

Address correspondence to Craig Garfield, MD, MAPP, Northwestern University Feinberg School of Medicine, Department of Medical Social Sciences, 633 St Clair, Suite 19-059, Chicago, IL 60611. E-mail: c-garfield@northwestern.edu PEDIATRICS (ISSN Numbers: Print, 0031-4005; Online, 1098-4275) Copyright (C) 2014 by the American Academy of Pediatrics FINANCIAL DISCLOSURE: The authors have indicated they have no financial relationships relevant to this article to disclose.

FUNDING: Supported by National Institutes of Health grant K23HD060664 to CFG from the Eunice Kennedy Shriver National Institute For Child Health and Development. Funded by the National Institutes of Health (NIH).

POTENTIAL CONFLICT OF INTEREST: The authors have indicated they have no potential conflicts of interest to disclose. 
National and international studies show screening rates of clinical paternal depression ranging from $5 \%$ to $10 \%{ }^{1-5}$ Depressed fathers exhibit poorer parenting behaviors, ${ }^{6}$ lower likelihood of child engagement, and greater likelihood of parenting stress and child neglect ${ }^{7}$ than non-depressed fathers. ${ }^{8}$ Children of depressed fathers are at risk for later psychiatric disorders, ${ }^{3}$ poorer language and reading development, ${ }^{9}$ and increased risks of behavior problems, including peer problems, conduct problems, and poorer prosocial behaviors across ages, than children of nondepressed fathers. ${ }^{2,5} \mathrm{Al}$ though studies show a decline in young men's physical health during the transition to fatherhood, ${ }^{10-12}$ less is known about the mental health of fathers during the transition. Several social factors may be implicated. ${ }^{13}$ First, offtime entry into fatherhood, in which men become fathers outside the typical timeframe for their generational peers, particularly during the adolescent years, may increase risk of depressive symptoms ${ }^{8,14}$ making the earlier years of fathering especially important in early childhood development. Second, father's living arrangements may play a role because nonresident fathers report higher levels of depression and anxiety.,15-20 Finally, race/ethnicity has been shown to be an important factor in depression in general with non-Hispanic blacks and Hispanics more likely to report major depression than non-Hispanic whites. ${ }^{21-23}$ No studies of paternal depression that we are aware of have examined these factors collectively over time before and after becoming a father. Given the significant negative consequences of paternal depression early on in fatherhood and the potential of exposing offspring during key early childhood developmental stages when fathers are in their early fathering years, understanding the progression of fathers' depression and delineating key points of potential intervention are paramount.
The developmental window across the life course during which fathers are at-risk or experience depression symptoms has not been well established. Life course theory posits that appropriately timed interventions hold the most promise for improved long-term outcomes and decreased disparities. ${ }^{24}$ One such successful application is a smoking cessation intervention designed specifically for fathers using the transition to fatherhood as an intervention point. ${ }^{25}$ Thus, understanding the evolution of paternal mental health along the life course may identify key windows with the greatest potential for interventions to improve the well-being of fathers and, ultimately, their children.

The primary goal of this study was to assess how the transition into fatherhood may be associated with changes in depression among men and whether this association differed by key social factors. Our data come from the National Longitudinal Study of Adolescent Health (Add Health), which followed a representative sample of American youth from adolescence through early adulthood (20745 total adolescents). The size, longitudinal scope, and national representation of Add Health provide an exceptional opportunity to investigate the determinants of mental health among males as they progress from adolescence into young adulthood. We examined a 2-sided hypothesis that change exists between fatherhood period and depressive symptoms. We further examined the association between changes in depression and key social factors.

\section{METHODS}

\section{Study Design and Sample}

Add Health is a nationally representative, longitudinal study of the social, behavioral, and biomedical health of 20745 youth begun in 1994 as they progress from adolescence into adulthood.
Wave I interviews (population $N=20$ 745 , male $n=10$ 263; overall response rate: $79 \%)$ were conducted in 1994 1995; Wave II ( $N=14738, n=7182 ; 88 \%)$ in 1996; Wave III $(N=15197, n=7167$ 77\%) 6 years later in 2001-2002, and Wave IV $(N=15701, n=7349 ; 80 \%)$ in 2007-2008. Add Health intentionally oversampled adolescents from various income, racial/ethnic, and disability subgroups ${ }^{26}$; study-supplied weights correct for this. Data were combined to support a continuous time analysis of participants' differing life stages across waves such that all variables had values for each year covered by the study. Our institutional review board approved this investigation.

\section{Measures}

\section{Depressive Symptoms}

All participants reported on their symptoms of depression at each wave of the survey using 10 items drawn from the well-validated Center for Epidemiologic Studies Depression Scale (CES-D) scale. ${ }^{27,28}$ We examined the mean, SD, and quartiles for all 10 questions across each wave; scores were averaged and standardized to create a total score with adequate internal reliability at each wave $\left(\alpha_{1}=\right.$ 0.762, $\alpha_{2}=0.767, \alpha_{3}=0.759, \alpha_{4}=$ $0.811),{ }^{29}$ using accepted methods. ${ }^{30-32}$ An age-adjusted standardized depressive symptoms score was created from this unadjusted score to control for differences of depressive symptoms across ages along fatherhoodyears. This age-adjusted depressive symptoms score was calculated by finding the expected value of the unadjusted score for each age and subtracting it from each participant's unadjusted score. The expected values were found by regressing all ages on the unadjusted standardized depressive symptoms score. Therefore, an increase or decrease in the ageadjusted depressive symptoms score 
is commensurable across all 3 groups throughout the fatherhood years. The changes in this score represent a relative change in a normally distributed depressive symptoms outcome.

\section{Fatherhood Status and Time in Fatherhood}

Fatherhood status was defined by using the household roster (reports on each member of their household) and live child data set (reports on each child they have fathered) in each wave. Men who had listed a biological child in the household roster or live child data set were categorized as a father. Father's residence was coded into 3 categories: resident fathers, nonresident fathers, and nonfathers. Resident or nonresident father classification was held constant through all future waves. Nonfathers were the referent group throughout the analyses.

We created a person-year file in which all relevant interview years of any given sample male's longitudinal record were broken into separate data records, each of which contained the male's identifcation number and demographic and mental health data used in the analysis. For these "fatherhood-year" records, fatherhood status in each of the possible years of the data collection period was calculated on the basis of wavespecific information regarding the age of the firstborn child. For example, a participant who first mentioned a 3year-old in wave IV was coded as having +3 fatherhood-years in wave IV and -3 fatherhood years in wave III (which was conducted 6 years before wave IV), -9 fatherhood years in wave II (which was conducted 12 years earlier) and -10 fatherhood years in wave I (which was conducted 13 years earlier). Data from males who were never observed to be fathers were centered at the mean age of entrance into fatherhood for all fathers in the sample, which was 23. Thus, "fatherhood years" for a nonfather observed when the nonfather was 26 are coded as +3 . This allows for comparisons of fatherhood-years over the 19-year span between nonfathers (14-33) and fathers $(-9$ to +10$)$ and resembles other approaches to defining personyears surrounding events of interest. ${ }^{15}$ The term "fatherhood-years" is used for fathers and nonfathers.

\section{Control Variables}

Covariates coded for each person-year observation included respondents' race/ethnicity and own mother's education (wave I), and education, physical health, income, marital status, and number of children (each wave). Race/ ethnicity was categorized as white, black, Asian, Hispanic, and other with white as the referent group for the analyses. Marital status was measured at entrance into fatherhood. Although there was a significant difference between resident and nonresident fathers and marital status, marital status was not collinear with fatherhood status and had minimal affect on regression coefficients when removed ( $\beta_{\text {diff }} \pm 0.005$ ); therefore, it was kept in the model.

TABLE 1 Characteristics of Fathers and Nonfathers Sample

\begin{tabular}{|c|c|c|c|c|}
\hline & Nonfathers & Nonresident Fathers & Resident Fathers & $P$ \\
\hline Age at fatherhood entrance ${ }^{a}$ & $\mathrm{~N} / \mathrm{A}$ & $21.9(4.0)$ & $25.6(3.9)$ & .36 \\
\hline Race $^{b}$ & & & & $<.001$ \\
\hline White & $3434(50.6)$ & $274(39.3)$ & $1460(53.3)$ & \\
\hline Black & $1331(19.6)$ & $274(39.3)$ & $520(19.0)$ & \\
\hline Hispanic & $1115(16.4)$ & $97(14.1)$ & $502(18.3)$ & \\
\hline Asian & $609(9.0)$ & $15(2.2)$ & $143(5.2)$ & \\
\hline Other & $302(4.5)$ & $26(3.8)$ & $113(4.1)$ & \\
\hline Mother's education ${ }^{b}$ & & & & $<.001$ \\
\hline Less than HS & $868(16.2)$ & $115(20.6)$ & $419(19.2)$ & \\
\hline $\begin{array}{l}\text { HS Graduate, Vocational School, } \\
\text { or Technical School }\end{array}$ & $2017(37.7)$ & $256(45.9)$ & $967(44.2)$ & \\
\hline Some college to college graduate & $1919(35.9)$ & $162(29.0)$ & $674(30.8)$ & \\
\hline $\begin{array}{l}\text { Some graduate school to } \\
\text { professional degree }\end{array}$ & $545(10.2)$ & $25(4.5)$ & $127(5.8)$ & \\
\hline Own education $\mathrm{n}^{\mathrm{b}, \mathrm{c}}$ & & & & $<.001$ \\
\hline Less than HS & $439(6.4)$ & $127(18.5)$ & $291(10.6)$ & \\
\hline $\begin{array}{l}\text { HS graduate, vocational school, } \\
\text { or technical school }\end{array}$ & 1357 (19.9) & $244(35.6)$ & $927(33.8)$ & \\
\hline Some college to college graduate & $2734(40.0)$ & $251(36.6)$ & $1227(44.8)$ & \\
\hline $\begin{array}{l}\text { Some graduate school to } \\
\text { professional degree }\end{array}$ & $588(8.6)$ & $15(2.2)$ & $140(5.1)$ & \\
\hline General health $^{\mathrm{a}}$ & $2.96(0.89)$ & $2.87(0.95)$ & $2.94(0.89)$ & $<.001$ \\
\hline Parent's income (wave I) ${ }^{\mathrm{b}}$ & & & & $<.001$ \\
\hline$<\$ 30000$ & $1696(29.7)$ & $262(38.9)$ & $784(29.2)$ & \\
\hline$\$ 30000-\$ 49999$ & $1355(23.7)$ & $137(20.4)$ & $596(22.2)$ & \\
\hline$\$ 50000-\$ 74999$ & $1214(21.3)$ & $84(12.5)$ & $447(16.6)$ & \\
\hline$>\$ 75000$ & $1442(25.3)$ & $189(28.1)$ & $862(32.1)$ & \\
\hline Personal income (wave IV) ${ }^{\mathrm{b}}$ & & & & $<.001$ \\
\hline$<\$ 30000$ & $698(18.5)$ & $137(36.3)$ & $294(15.8)$ & \\
\hline$\$ 30000-\$ 49999$ & $833(22.1)$ & $86(22.8)$ & $438(23.6)$ & \\
\hline$\$ 50000-\$ 74999$ & $852(22.6)$ & 79 (20.9) & $503(27.1)$ & \\
\hline$>\$ 75000$ & $1391(36.9)$ & 75 (19.9) & $621(33.5)$ & \\
\hline Number of children ${ }^{d}$ & $\mathrm{~N} / \mathrm{A}$ & $1.06(1-3)$ & $1.52(1-7)$ & $<.001$ \\
\hline Marital status $s^{b, c}$ & & & & $<.001$ \\
\hline Yes & $857(12.6)$ & $54(7.9)$ & $1975(72.1)$ & \\
\hline No & $5971(87.4)$ & $632(92.1)$ & $764(27.9)$ & \\
\hline
\end{tabular}

$P$ values derived from $t$ test for continuous variables and $\chi^{2}$ for categorical variables. HS, high school; N/A, not applicable. a Mean (SD).

b $n(\%)$

${ }^{c}$ As of 0 fatherhood-years.

d Mean (range). 


\section{Statistical Analysis}

Mean levels of depressive symptoms scores were first analyzed by using tests of differences (ie, 2-group $t$ tests, analysis of variance) over 2 social determinants of interest, fatherhood status and race/ethnicity. Next, a generalized estimating equation (GEE) model was estimated to control for other covariates and to measure depressive symptom change over time. The GEE allows for outcomes to correlate over time, features an exchangeable correlation structure, and does not impose stringent assumptions of means, variances, and distributions on longitudinal data. Missing data are handled under a missing completely at random structure. ${ }^{33}$

Using GEE, we estimate a spline model with 3 knots modeling 4 mutually exclusive time category intervals to evaluate possible nonlinear change before and after fatherhood and based on a life course perspective: adolescence (defined in our data to include -9 up to -4 fatherhood-years), late adolescence (from -4 up to 0 fatherhoodyears), early fatherhood (from 0 up to +5 fatherhood-years) and later fatherhood (from +5 up to +10 fatherhoodyears). Using splines has the benefit of estimating linear segments of timebased functions that might be nonlinear across the entire period. Analyses were performed by using Stata/SE 12.1.

\section{RESULTS}

\section{Descriptive Findings}

Of 10253 men in the sample, 6828 $(66.5 \%)$ were nonfathers, and 3425 $(33.5 \%)$ were fathers by wave 4 ; of those fathers, at the time of the child's birth 686 (20.03\%) were nonresident, and 2739 (79.97\%) were resident (Table 1). The majority of nonfathers and resident fathers were white, and equal numbers of nonresident fathers were white and black. Most resident fathers were married (78\%) compared
TABLE 2 CES-D Scale Questions and Descriptive Statistics of Standardized Items Used to Create Depressive Symptoms Scores at Entrance Into Fatherhood

\begin{tabular}{|c|c|c|c|c|c|c|}
\hline Question & Mean (SD) & Minimum & $25 \%$ & Median & $75 \%$ & Maximum \\
\hline $\begin{array}{l}\text { 1. You were bothered by things that do not } \\
\text { usually bother you. }\end{array}$ & -0.04 (0.99) & -0.79 & -0.77 & -0.75 & 0.66 & 3.54 \\
\hline $\begin{array}{l}\text { 2. You felt that you could not shake off the } \\
\text { blues, even with help from your family and } \\
\text { your friends. }\end{array}$ & $-0.06(0.94)$ & -0.59 & -0.52 & -0.52 & -0.51 & 4.11 \\
\hline $\begin{array}{l}\text { 3. You did not feel just as good as other } \\
\text { people. }^{\text {a }}\end{array}$ & $-0.04(1.01)$ & -1.06 & -0.78 & -0.78 & 0.28 & 2.51 \\
\hline $\begin{array}{l}\text { 4. You had trouble keeping your mind on } \\
\text { what you were doing. }\end{array}$ & $-0.07(0.97)$ & -1.03 & -0.83 & -0.83 & 0.51 & 3.19 \\
\hline 5. You felt depressed. & $-0.09(0.90)$ & -0.69 & -0.53 & -0.53 & -0.53 & 4.05 \\
\hline $\begin{array}{l}\text { 6. You felt that you were too tired to do } \\
\text { things. }\end{array}$ & $-0.12(0.90)$ & -1.11 & -0.88 & 0.16 & 0.48 & 3.21 \\
\hline 7. You felt unhappy. ${ }^{a}$ & -0 & -1.11 & -1.04 & 0.19 & 0.19 & 2.64 \\
\hline 8. You did not enjoy life. ${ }^{a}$ & $-0.05(0.99)$ & -0.93 & -0.78 & -0.78 & 0.42 & 2.94 \\
\hline 9. You felt sad. & $-0.10(0.93)$ & -0.86 & -0.75 & -0.75 & 0.72 & 3.66 \\
\hline 10. You felt that people disliked you. & $0.03(1.05)$ & -0.63 & -0.47 & -0.47 & -0.47 & 4.86 \\
\hline
\end{tabular}

Quartiles are not clinically based but represent scores distributed across our population. Ten-item subset of CES-D questions available in Add Health.

a These items were reversed coded from their typical direction. The language reflects this reversal. with nonresident fathers (8\%) and nonfathers (13\%).

The 10 CES-D depressive symptom scores and descriptive statistics are presented in Table 2. The cross-sectional mean depressive symptoms scores for fathers at 0 fatherhood-years and nonfathers at age 23 years are shown in Table 3. Scores at 0 fatherhood-years indicate that there are significant differences between the 3 groups, with resident fathers having significantly lower depressive symptoms than nonfathers, who in turn were significantly lower than nonresident fathers. Similarly, there are differing scores at 0 fatherhood-years by fatherhood category within certain races (Table 4) and differences in depression scores by race, with black and Hispanic men have higher mean scores than white men among both nonfathers and resident fathers (Table 5).

\section{Regression Results}

\section{Depression and Fatherhood Status}

The regression results in Table 6 show trends in depressive symptom scores for all 3 groups of fathers, with nonfathers as the referent group. For nonfathers, none of the 4 time slope estimates is statistically significant.

For resident fathers, however, the interaction variable between fatherhood status and the late adolescence time period is negative and statistically significant ( $\beta=-0.055, P=.02$ ) compared with nonfathers. This indicates that before becoming a resident father, depressive symptoms are occurring less often. Yet the child's birth reverses this downward trend; resident fathers show a statistically significant increase in the depressive symptoms score during early fatherhood ( $\beta=0.033, P=.04$ ) compared with nonfathers. Thus, from
TABLE 3 Cross-Sectional Descriptive Statistics of Standardized Depressive Symptoms Scores at Entrance into Fatherhood (Year 0) by Fatherhood Status

\begin{tabular}{lrcccrrrr}
\hline & Mean (SE) & SD & Minimum & $25 \%$ & Median & $75 \%$ & Maximum & $P$ \\
\hline Nonfathers & $-0.01(0.02)$ & 0.97 & -1.46 & -0.85 & -0.25 & 0.51 & 5.62 & $<.001^{\mathrm{a}}$ \\
Nonresident fathers & $0.29(0.05)$ & 1.02 & -1.46 & -0.85 & 0.01 & 0.76 & 5.62 & $<.001^{\mathrm{b}}$ \\
Resident fathers & $-0.08(0.02)$ & 0.95 & -1.46 & -0.85 & -0.25 & 0.52 & 4.92 & $.005^{\mathrm{c}}$ \\
\hline
\end{tabular}

Quartiles are not clinically based but represent CES-D scores distributed across our population

a Comparing nonfathers with nonresident fathers.

b Comparing nonresident fathers with resident fathers.

${ }^{\mathrm{c}}$ Comparing resident fathers with nonfathers. 
TABLE 4 Cross-Sectional Descriptive Statistics of Standardized Depressive Symptoms Scores at Entrance Into Fatherhood (Year 0) by Race and Fatherhood Status

\begin{tabular}{lrrccc}
\hline \multicolumn{1}{l}{ Mean (SE) } & SD & Minimum & Maximum & $P$ \\
\hline White & & & & & \\
$\quad$ Nonfathers & $-0.05(0.02)$ & 0.98 & -1.46 & 5.62 & $.001^{\mathrm{a}}$ \\
$\quad$ Nonresident fathers & $0.29(0.10)$ & 1.20 & -1.46 & 5.62 & $<.001^{\mathrm{b}}$ \\
$\quad$ Resident fathers & $-0.19(0.02)$ & 0.93 & -1.46 & 4.91 & $<.001^{\mathrm{c}}$ \\
Black & & & & & \\
$\quad$ Nonfathers & $0.06(0.04)$ & 1.01 & -1.46 & 4.56 & $.01^{\mathrm{a}}$ \\
$\quad$ Nonresident fathers & $0.30(0.09)$ & 1.10 & -1.46 & 4.81 & $.16^{\mathrm{b}}$ \\
$\quad$ Resident fathers & $0.16(0.06)$ & 1.02 & -1.46 & 4.91 & $.16^{\mathrm{c}}$ \\
Hispanic & & & & & \\
$\quad$ Nonfathers & $-0.02(0.04)$ & 1.01 & -1.46 & 5.38 & $.11^{\mathrm{a}}$ \\
$\quad$ Nonresident fathers & $0.20(0.13)$ & 1.03 & -1.46 & 3.53 & $.07^{\mathrm{b}}$ \\
$\quad$ Resident fathers & $-0.06(0.05)$ & 0.96 & -1.46 & 3.80 & $.55^{\mathrm{c}}$ \\
Asian & & & & & \\
$\quad$ Nonfathers & $0.12(0.05)$ & 0.96 & -1.46 & 5.62 & $.97^{\mathrm{a}}$ \\
$\quad$ Nonresident fathers & $0.11(0.31)$ & 0.91 & -1.27 & 1.85 & $.76^{\mathrm{b}}$ \\
$\quad$ Resident fathers & $0.21(0.12)$ & 0.94 & -1.46 & 5.37 & $.47^{\mathrm{b}}$ \\
Other & & & & & $.04^{\mathrm{a}}$ \\
$\quad$ Nonfathers & $0.05(0.08)$ & 1.06 & -1.46 & 5.62 & $.02^{\mathrm{b}}$ \\
$\quad$ Nonresident fathers & $0.57(0.21)$ & 0.89 & -1.26 & 2.78 & $.38^{\mathrm{c}}$ \\
$\quad$ Resident fathers & $-0.07(0.11)$ & 1.07 & -1.46 & 3.73 & \\
\hline
\end{tabular}

a Comparing nonfathers with nonresident fathers.

b Comparing nonresident fathers with resident fathers

c Comparing resident fathers with nonfathers.

entrance into fatherhood to the end of early fatherhood ( $0-5$ years), the depressive symptoms score for resident fathers increases by 0.023 per year, or by $0.115 \mathrm{U}$ over the 5 -year period. Taking the highest depressive symptom score, which occurs in the adolescent period $(-0.009)$, and subtracting the lowest score at the entrance to fatherhood $(-0.179)$, results in a difference of $0.170 \mathrm{U}$.
Considering this range, early residential fatherhood constitutes an average increase of $68 \%$ of the average resident father's total score. Early fatherhood therefore represents a period of large change in depressive symptoms for resident fathers. In contrast, none of the 4 coefficients on interaction terms representing nonresident fathers is statistically significant.

TABLE 5 Cross-Sectional Descriptive Statistics of Depressive Symptoms Scores at Entrance into Fatherhood (Year 0) by Fatherhood Status and Race

\begin{tabular}{|c|c|c|c|c|c|}
\hline & Mean (SE) & SD & Minimum & Maximum & $P^{a}$ \\
\hline Nonfathers & & & & & $<.001$ \\
\hline White & $-0.05(0.02)$ & 0.98 & -1.46 & 5.62 & \\
\hline Black & $0.06(0.04)$ & 1.01 & -1.46 & 4.56 & \\
\hline Hispanic & $-0.02(0.04)$ & 1.01 & -1.46 & 5.38 & \\
\hline Asian & $0.12(0.05)$ & 0.96 & -1.46 & 5.62 & \\
\hline Other & $0.05(0.08)$ & 1.06 & -1.46 & 5.62 & \\
\hline Nonresident fathers & & & & & .65 \\
\hline White & $0.29(0.10)$ & 1.20 & -1.46 & 5.62 & \\
\hline Black & $0.30(0.09)$ & 1.10 & -1.46 & 4.81 & \\
\hline Hispanic & $0.20(0.13)$ & 1.03 & -1.46 & 3.53 & \\
\hline Asian & $0.11(0.31)$ & 0.91 & -1.27 & 1.85 & \\
\hline Other & $0.57(0.21)$ & 0.89 & -1.26 & 2.78 & \\
\hline Resident fathers & & & & & $<.001$ \\
\hline White & $-0.19(0.02)$ & 0.93 & -1.46 & 4.91 & \\
\hline Black & $0.16(0.06)$ & 1.02 & -1.46 & 4.91 & \\
\hline Hispanic & $-0.06(0.05)$ & 0.96 & -1.46 & 3.80 & \\
\hline Asian & $0.21(0.12)$ & 0.94 & -1.46 & 5.37 & \\
\hline Other & $-0.07(0.11)$ & 1.07 & -1.46 & 3.73 & \\
\hline
\end{tabular}

a $P$ values from $F$ tests reported

Figure 1 illustrates the trajectories of age-adjusted depressive symptoms for resident and nonresident fathers taken from the regression coefficients; the 2 statistically significant periods are the decrease in resident fathers' scores before the child's birth and the increase in scores after the birth.

\section{Depression and Other Covariates}

Mother's education, own education, physical health, employment, marriage, and income level were all associated with lower levels of age-adjusted depressive symptoms scores (Table 6). There is evidence that each additional child is positively associated with depressive symptoms $(\beta=0.047, P<.05)$; limiting the range of children did not affect the outcome. Table 6 also shows that race is associated with mean levels of depressive symptoms scores. Compared with the referent group of white males, all other race/ethnicities reported a significantly higher level of depressive symptoms.

\section{DISCUSSION}

In the first study of its kind using nationally representative longitudinal data to follow depressive symptoms of young men during the transition to fatherhood, we find that resident fathers experience a decrease in depressive symptoms scores in the period immediately preceding entry into fatherhood but then have a $68 \%$ increase in their scores through the child's first 5 years of life. For children, the 0 to 5 years are key developmental years when attachment, security, and the ability to safely explore and learn in one's environment are of paramount importance. Parents are responsible for creating such environments. Unrecognized paternal depression during this time period, whether due to a lack of awareness or a lack of access to health care services for fathers, may adversely affect infant 
TABLE 6 Regression Results of Age-Adjusted Depressive Symptoms Score Over Fatherhood-Years

\begin{tabular}{|c|c|c|c|c|}
\hline Age-Adjusted Standardized Depression Score & $\beta$ & SE & $P$ & $95 \% \mathrm{Cl}$ \\
\hline Nonresident father ${ }^{\mathrm{a}}$ & 0.011 & 0.091 & .91 & -0.168 to 0.190 \\
\hline Resident father ${ }^{a}$ & -0.009 & 0.045 & .85 & -0.098 to 0.080 \\
\hline$(-9$ to -4$) \mathrm{FHY}$ & -0.007 & 0.009 & .48 & -0.025 to 0.012 \\
\hline Nonresident father $\times$ FHY & 0.027 & 0.027 & .31 & -0.025 to 0.080 \\
\hline Resident father $\times$ FHY & 0.006 & 0.015 & .71 & -0.024 to 0.035 \\
\hline$(-4,0) \mathrm{FHY}$ & 0.020 & 0.017 & .24 & -0.014 to 0.054 \\
\hline Nonresident father $\times$ FHY & -0.005 & 0.035 & .89 & -0.074 to 0.064 \\
\hline Resident father $\times \mathrm{FHY}^{*}$ & -0.055 & 0.024 & .02 & -0.103 to -0.007 \\
\hline$(0$ to +5$) \mathrm{FHY}$ & -0.010 & 0.012 & .40 & -0.035 to 0.014 \\
\hline Nonresident father $\times$ FHY & -0.015 & 0.028 & .59 & -0.071 to 0.040 \\
\hline Resident father $\times \mathrm{FHY}^{*}$ & 0.033 & 0.016 & .04 & -0.001 to 0.065 \\
\hline$(+5$ to +10$)$ FHY & -0.003 & 0.020 & .89 & -0.043 to 0.037 \\
\hline Nonresident father $\times$ FHY & -0.029 & 0.052 & .57 & -0.131 to 0.072 \\
\hline Resident father $\times$ FHY & -0.023 & 0.033 & .49 & -0.088 to 0.042 \\
\hline \multicolumn{5}{|l|}{ Covariates } \\
\hline Physical health ${ }^{\star \star}$ & -0.229 & 0.011 & $<.001$ & -0.249 to -0.208 \\
\hline Income $e^{\star \star}$ & -0.035 & 0.008 & $<.001$ & -0.051 to -0.019 \\
\hline Employment ${ }^{\star \star}$ & -0.074 & 0.017 & $<.001$ & -0.108 to -0.040 \\
\hline Black $^{\star \star}$ & 0.122 & 0.029 & $<.001$ & 0.066 to 0.178 \\
\hline Asian ${ }^{\star \star}$ & 0.296 & 0.045 & $<.001$ & 0.207 to 0.385 \\
\hline Latino* & 0.068 & 0.030 & .02 & 0.009 to 0.126 \\
\hline 0ther* & 0.131 & 0.054 & .02 & 0.025 to 0.237 \\
\hline Marital status ${ }^{\star \star}$ & -0.128 & 0.028 & $<.001$ & -0.184 to -0.073 \\
\hline Mother's education** & -0.04 & 0.013 & .002 & -0.066 to -0.014 \\
\hline Own education ${ }^{\star \star}$ & -0.078 & 0.010 & $<.001$ & -0.097 to -0.060 \\
\hline Number of children* & 0.047 & 0.024 & .05 & 0.001 to 0.093 \\
\hline Intercept & 0.953 & 0.049 & $<.001$ & 0.856 to 1.049 \\
\hline
\end{tabular}

* $P \leq .05 ;{ }^{*} P \leq .01$. $\mathrm{Cl}$, confidence interval; $\mathrm{FHY}$, fatherhood-years.

a Referent group is nonfathers.

and toddler development, parental relationships, and father well-being. The transition to fatherhood and early fatherhood years may indeed be optimal

time points along the life course trajectory to identify fathers at risk for or suffering from depressive symptoms and intervene.

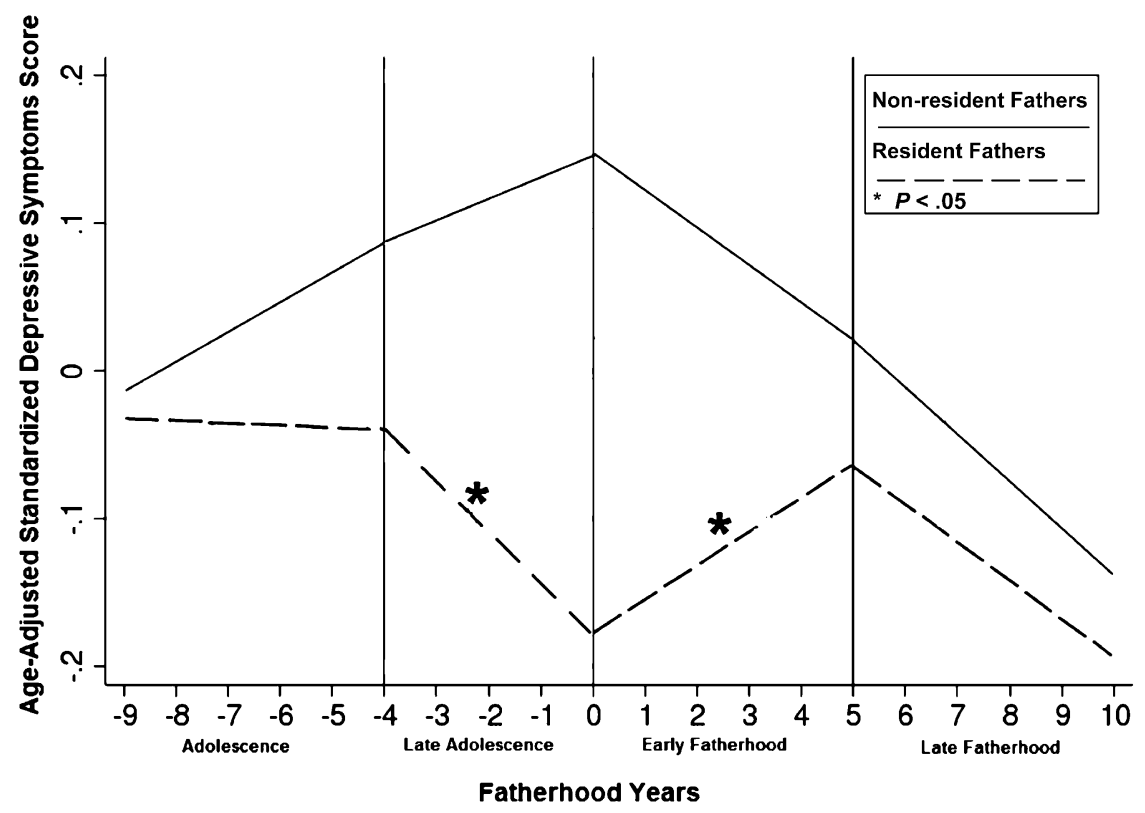

FIGURE 1

Change in depressive symptom scores across fatherhood-years from adolescence, later adolescence, early fatherhood, and late fatherhood among nonresident and resident US fathers.
Findings from the nonresident fathers and nonfathers groups, although not statistically significant, provide additional key context. In the years just before the transition to fatherhood (ie, late adolescence), young men who are not going to become a father have relatively stable scores, whereas those who will become nonresident fathers' show an increase and those who will become resident fathers show a decrease in scores. It is nonresident fathers reporting the highest levels of mean depressive symptoms scores among the 3 groups, reaching a maximum just before entering fatherhood. This confirms earlier research placing nonresident fathers at higher risk for depression. ${ }^{15,16}$ The lack of statistical significance may be due in part to smaller sample sizes; future studies with larger sample sizes, either from this data set as time passes or in others, are warranted. Some may argue that selection into fatherhood may be playing a role, with the strongest argument being that those with the lowest scores are likely to find a partner and become a resident father. Nevertheless, our findings show the unique path each group takes over time that plays a role when conceptualizing effective interventions and programs for young men.

Race/ethnicity, another key social factor, was associated with depressive symptoms scores with black and Hispanic fathers showing higher levels compared with whites at each data point and along the trajectories. This is consistent with previous research.8,21,22 For those races with higher baseline scores (ie, blacks, Hispanics), this relative increase in scores may result in a clinically significant rise in overall symptom scores. With other studies reporting that depression is highest among ethnic minority fathers, 8,28 special attention to the mental health of men of color is necessary. 
Viewing these results from a life course perspective, a number of implications emerge. First, nonresident and resident fathers have different mental health trajectories from late adolescence into early fatherhood. Therefore, designing strategies to identify these young men at the appropriate times is key to improving their well-being and that of their offspring. Of note, a growing body of research finds fathers present at pediatric visits, 34,35 suggesting that identifying at-risk fathers at these encounters is possible. Second, depressive symptom scores among nonfathers and nonresident fathers increase in late adolescence. If identified early enough and acted on, peak scores during the transition to fatherhood (or age 23 for nonfathers) may be diminished. This is likely to be true for black and Hispanic men who start with higher scores. Finally, when considering interventions, it is essential to remember that men of the child-rearing ages 18 to 44 are less likely to be engaged in the health care system, have a primary care physician, and have insurance compared with women, ${ }^{13,36}$ thereby making the identification of mental health problems difficult at the very time when the impact on children and families may be the greatest. Several initiatives, such as the Affordable Care Act $^{37}$ and a new focus on preconception care, ${ }^{38}$ offer potential to improve the care for young men.

Identifying changes in paternal mental health today faces similar challenges to identifying maternal mental health changes in the past. Chief among them is finding effective screening tools. Men are typically more willing to acknowledge fatigue, irritability, anhedonia, and sleep disturbances rather than reporting sadness, worthlessness, or guilt.28,39,40 Useful screens do exist, including the Edinburgh Postnatal Depression Scale, ${ }^{41}$ the 5 -item Mental Health Inventory, ${ }^{42}$ the 36 -item Short Form Health Survey, ${ }^{43}$ the General Health Questionnaire, ${ }^{44}$ the CES-D, ${ }^{27}$ and the Patient Health Questionnaire-2.45 The next issue to address is identifying next steps for those men who screen positive. This is a more formative hurdle; first, men are often reticent to seek help, and, second, finding appropriate referral sources for men may be difficult. 46,47 Comprehensive clinical interventions designed specifically for depressed fathers are minimal. ${ }^{11,48}$ The current study identifies the life course timing during which programs and interventions could be designed to address paternal depression.

The nature and timing of longitudinal data collection present several limitations. First, we have variable point estimates that we estimate to be linear but may be nonlinear. By using splines, we ensure our linear slopes provide reasonable estimates during each time period. Second, because of timing, our sample consists of younger fathers. However, resident fathers age of fatherhood entry, 25 , is the same as the National Survey of Family Growth's age at first birth for men from 2006 to $2010 .{ }^{49}$ We cannot generalize our findings to men who become fathers before age 18, who have been fathers for $>10$ years, or are older fathers. Finally, because we constrained the fatherhood status variable to 1 entry per participant, we cannot address the changes some fathers may have made from nonresident to resident or vice versa. Future research that can track these changes and the role these changes have on mental health is important.

\section{CONCLUSIONS}

With the growing appreciation of the role fathers play in the health and development of their children, understanding the natural history of paternal depression over the life course has implications for fathers' own well-being and involvement as well as the wellbeing of their children. In our longitudinal, population-based study, nonresident fathers showed an increase in depressive symptoms leading up to fatherhood, whereas resident fathers showed an increase in depression symptoms during their children's years 0 through 5 , key development years for child bonding and attachment. Identifying at-risk fathers and designing effective interventions may improve health outcomes for themselves, their children, and their family.

\section{REFERENCES}

1. Paulson JF, Bazemore SD. Prenatal and postpartum depression in fathers and its association with maternal depression. JAMA. 2010;303(19):1961-1969

2. Davé S, Sherr L, Senior R, Nazareth I. Associations between paternal depression and behaviour problems in children of 4-6 years. Eur Child Adolesc Psychiatry. 2008;17 (5):306-315

3. Ramchandani PG, Stein A, O'Connor TG, Heron JON, Murray L, Evans J. Depression in Men in the Postnatal Period and Later Child Psychopathology: A Population Cohort Study 2008;47(4):390-398

4. Davé S, Petersen I, Sherr L, Nazareth I. Incidence of maternal and paternal depression in primary care: a cohort study using a primary care database. Arch Pediatr Adolesc Med. 2010;164(11):10381044

5. Fletcher RJ, Feeman E, Garfield C, Vimpani $G$. The effects of early paternal depression on children's development. Med J Aust. 2011;195(11-12):685-689

6. Davis RN, Davis MM, Freed GL, Clark SJ. Fathers' depression related to positive and negative parenting behaviors with 1-yearold children. Pediatrics. 2011;127(4):612618

7. Lee $\mathrm{Cl}$, Bassett LW, Lehman CD. Breast density legislation and opportunities for patient-centered outcomes research. Radiology. 2012;264(3):632-636 
8. Bronte-Tinkew J, Moore KA, Matthews G, Carrano J. Symptoms of major depression in a sample of fathers of infants sociodemographic correlates and links to father involvement. J Fam Issues. 2007;28(1):61-99

9. Paulson JF, Keefe HA, Leiferman JA. Early parental depression and child language development. J Child Psychol Psychiatry. 2009;50 (3):254-262

10. Condon JT, Boyce P, Corkindale CJ. The First-Time Fathers Study: a prospective study of the mental health and wellbeing of men during the transition to parenthood. Aust N Z J Psychiatry. 2004;38(1-2):56-64

11. Bartlett EE. The effects of fatherhood on the health of men: a review of the literature. $J$ Mens Health Gend. 2004;1(2):159-169

12. Ferketich SL, Mercer RT. Men's health status during pregnancy and early fatherhood. Res Nurs Health. 1989;12(3):137-148

13. Garfield CF, Clark-Kauffman E, Davis MM. Fatherhood as a component of men's health. JAMA. 2006;296(19):2365-2368

14. Lee Y, Fagan J, Chen W-Y. Do late adolescent fathers have more depressive symptoms than older fathers? J Youth Adolesc. 2012; 41(10):1366-1381

15. Huang CC, Warner LA. Relationship characteristics and depression among fathers with newborns. Soc Serv Rev. 2005;79(1): 95-118

16. Jaffee SR, Caspi A, Moffitt TE, Taylor A, Dickson N. Predicting early fatherhood and whether young fathers live with their children: prospective findings and policy reconsiderations. J Child Psychol Psychiatry. 2001;42(6):803-815

17. Jefferis BJ, Nazareth $\mathrm{I}$, Marston L, et al. Associations between unemployment and major depressive disorder: evidence from an international, prospective study (the predict cohort). Soc Sci Med. 2011;73(11): 1627-1634

18. Lorant V, Deliège D, Eaton W, Robert A, Philippot P, Ansseau M. Socioeconomic inequalities in depression: a meta-analysis. Am J Epidemiol. 2003;157(2):98-112

19. Muntaner C, Eaton WW, Miech R, O'Campo P. Socioeconomic position and major mental disorders. Epidemiol Rev. 2004;26(1):53-62

20. Mossakowski KN. The influence of past unemployment duration on symptoms of depression among young women and men in the United States. Am J Public Health. 2009;99(10):1826-1832

21. Gonzalez 0, Berry J, McKnight-Eily L, et al; Centers for Disease Control and Prevention (CDC). Current depression among adultsUnited States, 2006 and 2008. MMWR Morb Mortal Wkly Rep. 2010;59(38):1229-1235
22. Walsemann KM, Gee GC, Geronimus AT. Ethnic differences in trajectories of depressive symptoms: disadvantage in family background, high school experiences, and adult characteristics. J Health Soc Behav. 2009;50(1):82-98

23. Satcher D. Mental Health: Culture, Race, and Ethnicity-A Supplement to Mental Health: A Report of the Surgeon General. Rockville, MD: Substance Abuse and Mental Health Services Administration; 2001

24. Heckman JJ. Skill formation and the economics of investing in disadvantaged children. Science. 2006;312(5782):1900-1902

25. Robertson LM, Douglas F, Ludbrook A, Reid $\mathrm{G}$, van Teijlingen $\mathrm{E}$. What works with men? A systematic review of health promoting interventions targeting men. BMC Health Serv Res. 2008;8(1):141

26. Chantala K. Guidelines for analyzing Add Health data. 2006. Available at: www.cpc. unc.edu/projects/addhealth/data/guides/wtguidelines.pdf. Accessed September 30, 2013

27. Radloff LS. The CES-D scale a self-report depression scale for research in the general population. Appl Psychol Meas. 1977;1 (3):385-401

28. Sutin AR, Terracciano A, Milaneschi Y, An Y, Ferrucci L, Zonderman AB. The trajectory of depressive symptoms across the adult life span. JAMA Psychiatry. 2013;70(8):803-811

29. Nunnally JC, Bernstein IH. Psychometric Theory. 3rd ed. New York, NY: McGraw-Hill; 1994

30. Adam EK, Chyu L, Hoyt LT, et al. Adverse adolescent relationship histories and young adult health: cumulative effects of Ioneliness, low parental support, relationship instability, intimate partner violence, and loss. J Adolesc Health. 2011;49(3):278286

31. Rushton JL, Forcier M, Schectman RM. Epidemiology of depressive symptoms in the National Longitudinal Study of Adolescent Health. J Am Acad Child Adolesc Psychiatry. 2002;41 (2):199-205

32. Shrier LA, Harris SK, Sternberg M, Beardslee WR. Associations of depression, self-esteem, and substance use with sexual risk among adolescents. Prev Med. 2001;33(3):179-189

33. Zeger SL, Liang K-Y. Longitudinal data analysis for discrete and continuous outcomes. Biometrics. 1986;42(1):121-130

34. Garfield CF, Isacco A. Fathers and the wellchild visit. Pediatrics. 2006;117(4). Available at: www.pediatrics.org/cgi/content/full/117/4/ e637

35. Moore T, Kotelchuck M. Predictors of urban fathers' involvement in their child's health care. Pediatrics. 2004;113(3 pt 1):574-580
36. Garfield CF, Isacco AJ III. Urban fathers' involvement in their child's health and healthcare. Psychol Men Masc. 2012;13(1):32

37. Center for Medicare and Medicaid Services. Fact Sheet: How the Affordable Care Act is Helping Men Lead Healthier Lives \& Afford Health Insurance. 2013. Available at: www. cms.gov/Newsroom/MediaReleaseDatabase/ Fact-Sheets/2013-Fact-Sheets-Items/2013-0614.html. Accessed September 30, 2013

38. Frey KA, Navarro SM, Kotelchuck M, Lu MC The clinical content of preconception care: preconception care for men. Am J Obstet Gynecol. 2008;199(6 suppl 2):S389-S395

39. Magovcevic M, Addis ME. The Masculine Depression Scale: development and psychometric evaluation. Psychol Men Masc. 2008;9(3):117-132

40. Cochran SV, Rabinowitz FE. Men and Depression: Clinical and Empirical Perspectives. San Diego, CA: Academic Press; 1999

41. Matthey S, Barnett B, Kavanagh DJ, Howie P Validation of the Edinburgh Postnatal Depression Scale for men, and comparison of item endorsement with their partners. $J$ Affect Disord. 2001;64(2-3):175-184

42. Cuijpers P1, Smits N, Donker T, ten Have M, de Graaf R. Screening for mood and anxiety disorders with the five-item, the three-item, and the two-item Mental Health Inventory. Psychiatry Res. 2009 Aug 15;168(3):250-255

43. Berwick DM, Murphy JM, Goldman PA, Ware JE Jr, Barsky AJ, Weinstein MC. Performance of a five-item mental health screening test. Med Care. 1991;29(2):169176

44. Goldberg DP. Manual of the General Health Questionnaire. Windsor, England: NFER Publishing; 1978

45. Kroenke K, Spitzer RL, Williams JB. The Patient Health Questionnaire-2: validity of a two-item depression screener. Med Care 2003;41(11):1284-1292

46. Addis ME, Mahalik JR. Men, masculinity, and the contexts of help seeking. Am Psychol. 2003;58(1):5-14

47. Mansfield AK, Addis ME, Mahalik JR. Why won't he go to the doctor?": the psychology of men's help seeking. Int $J$ Mens Health. 2003;2(2):93-109

48. Habib C. Paternal perinatal depression: an overview and suggestions towards an in tervention model. J Fam Stud. 2012;18(1):416

49. Martinez G, Daniels K, Chandra A. Fertility of men and women aged 15-44 years in the United States: National Survey of Family Growth, 2006-2010 (National Health Statistics Reports 51). Atlanta, GA: Centers for Disease Control and Prevention; 2012 